\title{
Fat Emulsion
}

National Cancer Institute

\section{Source}

National Cancer Institute. Fat Emulsion. NCI Thesaurus. Code C2575.

A liquid composed of two immiscible substances, typically some form of fat and water. In parenteral nutrition, a fat emulsion may contain phospholipids, triglycerides and essential fatty acids ( $\mathrm{NCl04)}$ 